\title{
Low-dose methoxyflurane analgesia in adolescent patients with moderate-to-severe trauma pain: a subgroup analysis of the STOP! study
}

This article was published in the following Dove Medical Press journal: Journal of Pain Research

\section{Stuart Hartshorn' \\ Patrick Dissmann ${ }^{2}$ \\ Frank Coffey ${ }^{3}$ \\ Mark Lomax ${ }^{4}$}

'Emergency Department, Birmingham Children's Hospital, Birmingham, UK; ${ }^{2}$ Academic Department of Emergency Medicine, James Cook University Hospital, Middlesbrough, UK; ${ }^{3}$ DREEAM: Department of Research and Education in Emergency Medicine, Acute Medicine and Major Trauma, Nottingham University Hospitals NHS Trust, Nottingham, UK; ${ }^{4}$ Data Management \& Statistics, Mundipharma Research Limited, Cambridge, UK
Correspondence: Stuart Hartshorn Emergency Department, Birmingham Children's Hospital, Steelhouse Lane, Birmingham B4 6NH, UK

Tel +44 I II 3339527

Fax +44 I2I 333 950।

Email stuart.hartshorn@nhs.net
Introduction: The undertreatment of acute pain presents a significant challenge in the Emergency Department. This post hoc subgroup analysis of a previously reported randomized controlled UK study reports the efficacy and safety of low-dose methoxyflurane analgesia in treating adolescent patients with moderate-to-severe trauma pain.

Patients and methods: Three hundred patients ( 96 in the adolescent subgroup) aged $\geq 12$ years requiring analgesia for acute trauma pain (pain score of 4-7 on the Numerical Rating Scale) at triage were randomized 1:1 to methoxyflurane (up to $6 \mathrm{~mL}$ ) or placebo (normal saline), both administered using a Penthrox ${ }^{\circledR}$ inhaler. The patient could request rescue medication (paracetamol/opioids) at any time. The primary endpoint was the change from baseline in visual analog scale (VAS) pain intensity.

Results: Mean VAS pain score for the adolescent subgroup at baseline was $\sim 61 \mathrm{~mm}$. Adjusted mean change in VAS pain intensity from baseline to 5, 10, 15, and 20 minutes was $-24.5,-28.1$, -31.6 , and $-31.7 \mathrm{~mm}$ for methoxyflurane and $-14.6,-18.8,-19.2$, and $-23.7 \mathrm{~mm}$ for placebo, with a statistically significant treatment effect in favor of methoxyflurane overall across all four time points $(-9.9 \mathrm{~mm}$; 95\% CI: $-17.4,-2.4 \mathrm{~mm} ; P=0.0104)$. Median time to first pain relief was significantly shorter with methoxyflurane ( 1 minute) than placebo ( 3 minutes, $P<0.0001$ ). Pain relief was reported within 1-10 inhalations in $95.7 \%$ of methoxyflurane-treated patients and $64.6 \%$ of placebo-treated patients. Rescue medication was requested by two $(4.3 \%)$ methoxyflurane-treated patients and three (6.3\%) placebo-treated patients. Over $95 \%$ of patients, physicians, and nurses rated methoxyflurane treatment as "Excellent", "Very Good" or "Good" compared with between $64 \%$ and $68 \%$ for placebo. The incidence of adverse events was higher with methoxyflurane (51\%) than placebo (42\%), mostly comprising mild/transient dizziness and headache.

Conclusion: This subgroup analysis shows that low-dose inhaled methoxyflurane is a rapidacting and effective analgesic in adolescent patients presenting with moderate-to-severe trauma pain.

Trial registration: Clinicaltrials.gov identifier: NCT01420159, EudraCT number: 2011-000338-12.

Keywords: acute pain, analgesic, emergency department, injury, pediatric, Penthrox

\section{Introduction}

Pain is the most frequent complaint in the emergency setting,,$^{1,2}$ yet suboptimal evaluation and treatment of acute pain are still common. ${ }^{2-4}$ This may be due to underassessment of pain, especially if pain is evaluated based on visible signs rather than on patient reports of pain. ${ }^{5}$ It has been demonstrated that nurses significantly underestimate 
acute musculoskeletal pain in adult patients in the emergency department (ED). ${ }^{6}$ Along with underassessment of pain, other factors such as lack of formal training or practice variations in pain management, time constraints, opiophobia, and access to medications increase the likelihood of oligoanalgesia. ${ }^{4,7,8}$

Low frequency of pain severity assessment $(\sim 18 \%-32 \%)$ has also been reported for children with acute pain and traumatic injuries in the prehospital setting. ${ }^{9-11}$ Fewer than half of such patients receive analgesia from paramedics ${ }^{11-13}$ or within 1 hour of arrival at the ED. ${ }^{14}$ Younger patients are less likely to have a documented assessment of pain intensity or receive adequate pain medication. ${ }^{11,12,14}$ Even when analgesia is provided, pediatric patients are frequently under-dosed ${ }^{15}$ and only a small proportion achieve adequate pain relief. ${ }^{14}$ Consequently, assessment and management of pediatric pain in emergency care is a research priority. ${ }^{16,17}$ Intranasal (IN) or inhaled delivery of analgesic agents allow rapid and simple drug administration without the distress of intravenous (IV) placement or delay while oral or topical analgesics take effect, and may provide another option for the management of acute moderate-to-severe pain in children both in the prehospital and ED settings.

Methoxyflurane has well documented analgesic properties at low doses. ${ }^{18}$ Since discontinuation of its use as an anesthetic in the late 1970s due to reports of nephrotoxicity ${ }^{19-21}$ and the introduction of newer anesthetic agents, methoxyflurane has continued to be used in Australia and New Zealand $(3 \mathrm{~mL}$ dose in a handheld inhaler; Penthrox ${ }^{\circledR}$, Medical Developments International, Scoresby, VIC Australia) as a self-administered, rapid-acting analgesic agent for short-term relief of acute pain in adults and children in emergency medicine and for minor surgical and dental procedures. ${ }^{22,23}$ More recently, methoxyflurane has been licensed in Europe for the emergency relief of moderate-to-severe pain in conscious adults with trauma and associated pain, ${ }^{24}$ as well as in other territories including Asia, Eastern Europe, Latin America, South Africa, and the Gulf Area. Methoxyflurane is administered via a lightweight, handheld, green pen-shaped plastic disposable inhaler, which in Europe is supplied with an activated carbon chamber to reduce environmental exposure.

Studies of low-dose methoxyflurane indicate that it is an efficacious analgesic in the ED and prehospital settings ${ }^{25-27}$ and for procedural analgesia. ${ }^{28}$ The physiochemical characteristics of methoxyflurane mean that absorption is rapid, hence it has a fast onset of analgesia (usually within 6-10 inhalations). ${ }^{24,29}$ Two observational case series, ${ }^{30,31}$ a retrospective comparative study vs IV morphine and IN fentanyl ${ }^{32}$ and a pilot randomized controlled trial $(\mathrm{RCT})^{33}$ have also demonstrated rapid efficacy and high patient/health care provider (HCP) satisfaction with low-dose methoxyflurane analgesia in children with acute trauma pain; however, there is a paucity of data for pediatric patients from larger RCTs or outside of Australia.

The STOP! study was a UK-based RCT that investigated the short-term efficacy and safety of low-dose methoxyflurane analgesia ( $3 \mathrm{~mL}$ dose) for the treatment of moderateto-severe pain in 300 patients aged $\geq 12$ years presenting to the ED with moderate-to-severe trauma-related pain. The results for the full study population ${ }^{34}$ and adult subgroup aged $\geq 18$ years ${ }^{35}$ have previously been reported. The focus of this secondary paper is a post hoc subgroup analysis that evaluated efficacy and safety data for adolescent patients aged 12-17 years inclusive.

\section{Material and methods \\ Study design}

STOP! was a randomized, double-blind, multicenter, placebocontrolled study conducted at six EDs in the UK between August 05, 2011 and July 26, 2012. Patients presenting to the ED with moderate-to-severe acute trauma-related pain were randomized 1:1 to treatment with methoxyflurane (up to $2 \times 3$ $\mathrm{mL}$ ) or placebo, each administered via a Penthrox inhaler, as required while in the ED. Assessments including visual analog scale (VAS) pain intensity, rescue medication use, medication performance, and adverse events were performed by a blinded research nurse in the ED, and a safety follow-up visit was conducted $14 \pm 2$ days after ED discharge. The randomized study population $(\mathrm{N}=300)$ included 96 adolescent patients (aged 12-17 years) whose data are presented in this report. The full methodology for this study has been previously described in the primary publication. ${ }^{34}$ The study was conducted in accordance with the Declaration of Helsinki, International Council on Harmonization Good Clinical Practice, and local guidelines. The protocol and amendments were reviewed and approved by each participating National Health Service ethics committee and each study site's research and development department. Favorable opinion for the study was received from the National Research Ethics Service (REC reference 11/YH/0116). All patients (or the patient's parent or legal representative, if the patient was under 16 years of age) provided written informed consent before study enrollment.

\section{Study participants}

Patient eligibility for the study was established at triage after presentation to the ED. Patients aged $\geq 12$ years with moderate-to-severe pain (score of 4-7 on the 11-point Numerical Rating Scale [NRS]) due to minor trauma and requiring analgesia were enrolled. In this study, trauma referred to a 
physical wound or injury, such as dislocations, contusions, fractures, lacerations, burns or injury due to a foreign body. For this adolescent subgroup analysis, all patients were aged 12-17 years.

Patients were excluded from the study if they met any of the following criteria: analgesic use within 5 hours before presentation to the ED ( 8 hours for diclofenac sodium); ongoing analgesic use for chronic pain; methoxyflurane use within 4 weeks before enrollment; history of hypersensitivity to fluorinated anesthetics; clinically significant respiratory depression, cardiovascular instability, renal or hepatic impairment; acute intoxication with alcohol or drugs; a life-threatening condition requiring immediate admission to the operating room or intensive care unit.

\section{Treatments}

Patients were randomized in a 1:1 ratio to treatment with methoxyflurane (up to $2 \times 3 \mathrm{~mL}$ ) or placebo (sterile normal saline), self-administered as required by the patient via a Penthrox inhaler, assisted where required by the research nurse. The Penthrox inhaler is a lightweight, handheld, single-use green cylindrical device with a whistle-like mouthpiece at one end. Methoxyflurane is absorbed by an internal polypropylene wick and vaporizes within the inhaler, and is inhaled by the patient through the mouthpiece. Patients are instructed to also exhale through the inhaler so that unmetabolized methoxyflurane can be absorbed by the activated carbon chamber attached to the device, avoiding occupational exposure. The amount of methoxyflurane (and thus the degree of analgesia) is controlled by the patient by inhaling more or less frequently from the device. Initially, the patient was provided with one inhaler; a second inhaler was available upon request of the patient. One inhaler was predicted to provide up to 1 hour's pain relief with intermittent use. The patient could inhale a higher concentration of study medication, if required, by covering the diluter hole at the mouthpiece end of the inhaler with their index finger. The Penthrox inhaler provides a methoxyflurane concentration of $0.1 \%-0.2 \%$ with the diluter hole open, which increases to $0.3 \%-0.4 \%$ with diluter hole occlusion. ${ }^{36}$ Since this was a placebo-controlled study, rescue medication (IV, IN or oral opioids or paracetamol) was available at any time upon request of the patient, as recommended in the CHMP guideline CPMP/EWP/612/00 37 and guidance from the Declaration of Helsinki. Patients were provided with $16 \times 500 \mathrm{mg}$ paracetamol tablets at ED discharge for the treatment of pain, as needed, during the $14 \pm 2$ day safety follow-up period.

\section{Randomization and blinding}

Randomization was performed by an independent statistician using permuted blocks and was stratified by center and age group (adolescent/adult). Patients were assigned the next randomization number in the appropriate stratum at enrollment. Study medication was assembled and dispensed in a sealed plastic bag by an unblinded research team member. Prior to sealing the bag, a drop of methoxyflurane was placed on the outside of each inhaler, so that all inhalers had the characteristic fruity odor of methoxyflurane and the smell between active and placebo inhalers was indistinguishable upon opening the bag. To maintain the blind with regard to inhaler weight, $5 \mathrm{~mL}$ of saline solution was used in the placebo inhalers compared with $3 \mathrm{~mL}$ of methoxyflurane in the active inhalers, since the relative density of methoxyflurane (1.42) is greater than that of normal saline (1). The investigator, patient, and all site personnel (except the staff member responsible for dispensing study medication) were blinded to the treatment assignment.

\section{Efficacy assessments}

Study assessments were performed by a blinded research nurse, who remained with the patient in the ED while they were receiving care. Pain intensity was assessed using the Painlog ${ }^{\text {TM}} 100$ mm VAS (Schlenker Enterprises, Ltd., Lombard, IL, USA) at the following time points: baseline, 5, 10, 15,20 , and 30 minutes after the start of study treatment, then every 30 minutes until administration of rescue medication or discharge from the ED, whichever occurred first. The pain VAS is easy to use, does not require verbal or reading skills, and is commonly used in pain studies. ${ }^{38,39}$

The time from the start of treatment to first pain relief (subjectively reported by the patient), the number of inhalations taken before pain relief was reported by the patient, and use of the diluter hole during inhalation were recorded. Any rescue medication use was recorded, including the time of the request for rescue relative to the start of study treatment. A global assessment of medication performance (GMP) assessed using a 5-point Likert scale ("Poor", "Fair", "Good", "Very Good", or "Excellent") was completed separately by the patient, the treating physician, and the research nurse before ED discharge.

\section{Safety assessments}

Patients were observed by a research nurse throughout their stay in the ED. All adverse events (except those relating to the trauma presentation) were recorded from enrollment until ED 
discharge, with any subsequent adverse events being recorded at the safety follow-up visit on Day $14 \pm 2$. For each adverse event, the investigator assessed the relationship to study treatment and evaluated its severity. Vital signs, including blood pressure, heart rate and rhythm, and respiratory rate, were measured at the same time points as pain intensity. Blood samples were taken for safety laboratory tests (full blood count and clinical chemistry) at the start of study treatment and at the follow-up visit. The 15-point Glasgow coma score was used to assessed the patient's level of consciousness at 10,20 , and 30 minutes after the start of study medication inhalation and prior to ED discharge.

\section{Statistical analyses}

The modified intention-to-treat (ITT) population (including all randomized patients who used the study medication and had at least one on-treatment efficacy assessment) was used for all efficacy analyses. The primary efficacy variable was the change from baseline in VAS pain intensity at 5, 10, 15 , and 20 minutes after the start of study treatment. The change at each time point was analyzed using a repeatedmeasures analysis of covariance adjusted for baseline VAS score, and time-treatment interaction. Treatment effects (methoxyflurane vs placebo) were estimated as least squares mean differences. The primary analysis was the overall test for treatment effect across all four time points. Time to first pain relief and time to request for rescue medication were compared between the treatments using a Cox proportional hazards model adjusted for baseline VAS score. Time was censored at 2 hours after the start of treatment, physicianinitiated rescue medication, start of treatment for the injury, or early withdrawal, whichever occurred first. GMP ratings by the patient, research nurse, and treating physician at discharge were each compared between the treatments using ordinal logistic regression with proportional odds assumption adjusted for baseline VAS. Baseline was defined as the last recorded value before the start of study treatment; if the baseline value was missing, change from baseline was not calculated (ie, no imputation was performed). All hypothesis testing was performed at the 5\% (two-sided) significance level. The analyses performed for the adolescent subgroup mirrored the original study analysis methods, ${ }^{34}$ with the exception of removing the redundant term for age group (adult/adolescent). Other efficacy endpoints were summarized descriptively.

Adverse events were summarized for the safety population, defined as all randomized patients who used the study medication. Adverse events were classified as treatment-emergent if they started or increased in severity after the start of study treatment. Adverse events were coded using the Medical Dictionary for Regulatory Activities (MedDRA version 14.0) coding system. Statistical analyses were performed using $\mathrm{SAS}^{\circledR}$ version 9.4.

\section{Sample size}

The original sample size calculation estimated that 150 patients per treatment group in the whole study (adult and adolescent patients) would provide at least $94.5 \%$ power to detect a treatment difference of $13 \mathrm{~mm}^{40}$ in the overall change from baseline of VAS pain score over the first 20 minutes of treatment. The drop-out rate was expected to be minimal in this setting, therefore a sample size of 150 patients per arm was considered adequate, and was achieved in the study (300 patients randomized). However, the study sample size was not intended to provide sufficient power to demonstrate a statistically significant treatment difference in the adolescent-only subgroup presented in this report (96 patients randomized).

\section{Results \\ Study patients}

Participant flow for the adolescent subgroup is presented in Figure 1. Ninety-eight adolescent patients were screened; 96 of these patients were randomized to double-blind treatment (48 to each treatment group) and two patients were ineligible. One patient randomized to the methoxyflurane group was withdrawn before receiving study treatment due to the decision of the investigator, thus 95 adolescent patients were treated and included in the modified ITT and safety populations. All except two of the treated patients (both lost to follow-up) completed the study to Day $14 \pm 2$.

Patient demographic characteristics, baseline pain severity, and injury type were similar for both treatment groups (Table 1). The mean age of patients in the adolescent subgroup was 14 years and the majority of patients $(85.3 \%)$ were White. More male (70.5\%) than female $(29.5 \%)$ adolescent patients were enrolled. More than half of the patients $(55.8 \%)$ had an injury type of "other" (generally soft tissue injuries, sprains, and muscular pain), $23.2 \%$ had fractures, $15.8 \%$ had contusions, while lacerations, dislocations, and injuries due to foreign body were reported for one or two patients each. Only one patient had more than one injury (contusion and abrasion to shoulder, knee, and finger). Patients enrolled in the study were required to have moderate-to-severe pain (NRS score of 4-7) at baseline; accordingly, the mean (SD) baseline VAS pain intensity score was 61.7 (16.56) $\mathrm{mm}$ in the methoxyflurane group and $61.0(13.33) \mathrm{mm}$ in the placebo group. ${ }^{41}$ 


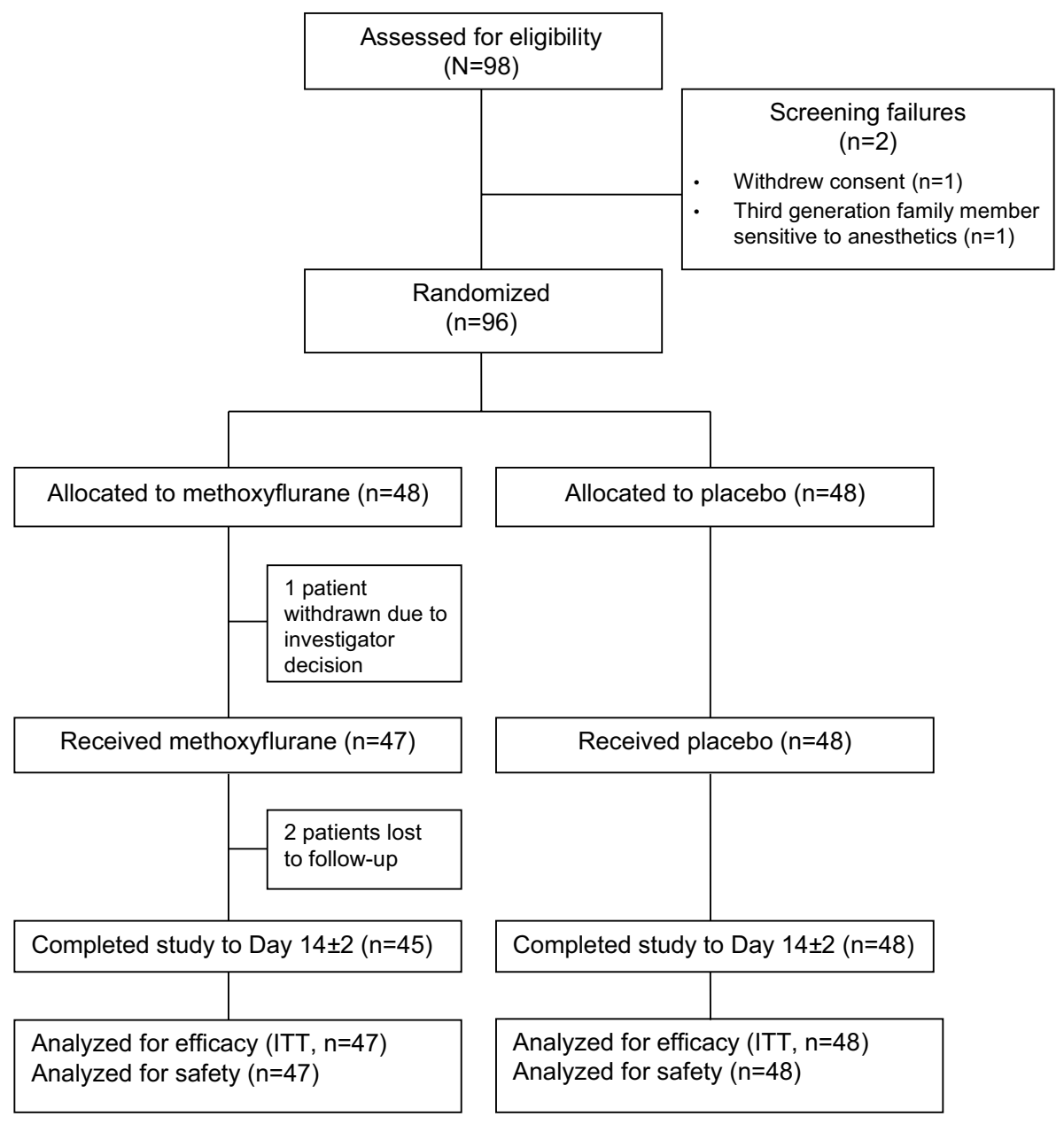

Figure I Participant flow.

Abbreviation: ITT, intention-to-treat.

\section{Pain relief}

The reduction in pain intensity was significantly greater with methoxyflurane than placebo in adolescent patients. The adjusted mean change from baseline to $5,10,15$, and 20 minutes for VAS pain intensity was $-24.5,-28.1,-31.6$, and $-31.7 \mathrm{~mm}$, respectively, for methoxyflurane and -14.6 , $-18.8,-19.2$, and $-23.7 \mathrm{~mm}$, respectively, for placebo, with a statistically significant treatment difference over the first 20 minutes of $-9.9 \mathrm{~mm}(95 \% \mathrm{CI}$ : -17.4 to $-2.4 \mathrm{~mm} ; P=0.0104$; Table 2). The largest treatment difference was at 15 minutes after the start of inhalation (estimated treatment effect: -12.4 $\mathrm{mm}$; $95 \% \mathrm{CI}:-21.9$ to $-2.9 \mathrm{~mm}$ ). Further reductions in pain intensity were observed beyond 20 minutes after the start of methoxyflurane inhalation, with mean decreases from baseline in VAS pain of $-38.7,-37.8$, and $-42.5 \mathrm{~mm}$ at $30(\mathrm{n}=32)$, $60(\mathrm{n}=5)$, and 90 minutes $(\mathrm{n}=2)$. In the placebo group, mean decreases of $-30.9,-26.9$, and $-31.0 \mathrm{~mm}$ were observed at $30(n=26), 60(n=7)$, and 90 minutes $(n=2)$. Fewer patients had available data at later time points due to discharge or undergoing further interventions.

Pain relief was reported by 46 of 47 methoxyfluranetreated patients $(97.9 \%)$, with a median time to pain relief of 1 minute (95\% CI: $1-2$ minutes). In the placebo group, pain relief was reported by 39 of 48 patients $(81.3 \%)$, with a median time to pain relief of 3 minutes (95\% CI: $2-5$ minutes). The time to first pain relief was significantly shorter in the methoxyflurane group compared with the placebo group (HR: $2.35 ; 95 \%$ CI: 1.48, 3.76; $P=0.0003$ ). Pain relief was experienced within $1-5$ inhalations for $61.7 \%$ of patients in the methoxyflurane group and $22.9 \%$ of patients in the placebo group, and within 1-10 inhalations for $95.7 \%$ and $64.6 \%$ of patients, respectively (Figure 2 ).

\section{Inhaler and rescue medication use}

Most patients required only one inhaler. A second inhaler was used by six (12.8\%) methoxyflurane-treated patients 
Table I Demographic and baseline characteristics (modified intention-to-treat population)

\begin{tabular}{|c|c|c|c|c|}
\hline Variable & Statistic & $\begin{array}{l}\text { Methoxyflurane } \\
(n=47)\end{array}$ & $\begin{array}{l}\text { Placebo } \\
(n=48)\end{array}$ & $\begin{array}{l}\text { Total } \\
(\mathrm{N}=95)\end{array}$ \\
\hline \multirow[t]{3}{*}{ Age (years) } & $\mathrm{n}$ & 47 & 48 & 95 \\
\hline & Mean (SD) & $14.4(1.4)$ & I3.5 (I.5) & $14(1.5)$ \\
\hline & Median (range) & $14(12-17)$ & $13(12-17)$ & $14(12-17)$ \\
\hline \multirow[t]{2}{*}{ Gender, n (\%) } & Male & $32(68.1)$ & $35(72.9)$ & $67(70.5)$ \\
\hline & Female & $15(31.9)$ & $13(27.1)$ & $28(29.5)$ \\
\hline \multirow[t]{4}{*}{ Race, n (\%) } & White & $41(87.2)$ & $40(83.3)$ & $81(85.3)$ \\
\hline & Asian & 0 & $5(10.4)$ & $5(5.3)$ \\
\hline & Black & $I(2.1)$ & $I(2.1)$ & $2(2.1)$ \\
\hline & Other & $5(10.6)$ & $2(4.2)$ & $7(7.4)$ \\
\hline Injury type, n (\%) & Other & $24(5 I .1)$ & $29(60.4)$ & $53(55.8)$ \\
\hline \multirow[t]{5}{*}{ (first injury } & Fracture & II (23.4) & II (22.9) & $22(23.2)$ \\
\hline & Contusion & $9(19.1)$ & $6(12.5)$ & $15(15.8)$ \\
\hline & Dislocation & $I(2.1)$ & $I(2.1)$ & $2(2.1)$ \\
\hline & Laceration & $\mathrm{I}(2.1)$ & $\mathrm{I}(2.1)$ & $2(2.1)$ \\
\hline & Injury due to foreign body & $I(2.1)$ & 0 & $\mathrm{I}(\mathrm{I} . \mathrm{I})$ \\
\hline \multirow[t]{7}{*}{ Site, n (\%) } & Right upper limb & $13(27.7)$ & $14(29.2)$ & $27(28.4)$ \\
\hline & Left upper limb & $13(27.7)$ & $8(16.7)$ & $21(22.1)$ \\
\hline & Right lower limb & $6(12.8)$ & II (22.9) & $17(17.9)$ \\
\hline & Left lower limb & $5(10.6)$ & $9(18.8)$ & $14(14.7)$ \\
\hline & Other & $7(14.9)$ & $4(8.3)$ & $11(11.6)$ \\
\hline & Face & $2(4.3)$ & I (2.I) & $3(3.2)$ \\
\hline & Back & $\mathrm{I}(2.1)$ & $\mathrm{I}(2.1)$ & $2(2.1)$ \\
\hline VAS pain intensity & & 45 & 47 & - \\
\hline \multirow[t]{2}{*}{$(\mathrm{mm})$} & Mean (SD) & $61.7(16.56)$ & $61.0(13.33)$ & - \\
\hline & Median (range) & $64(23-100)$ & $58(35-87)$ & - \\
\hline
\end{tabular}

Notes: ane patient had >I injury (second and third injuries were contusion and abrasion to knee and finger). "-” indicates data not available.

Abbreviation: VAS, visual analog scale.

Table 2 Analysis of visual analog scale (VAS) pain intensity score (modified intention-to-treat population)

\begin{tabular}{|l|l|l|l|l|}
\hline \multirow{2}{*}{ Time point } & \multicolumn{2}{|l|}{ Adjusted $^{\mathbf{a}}$ mean change from baseline } & Estimated treatment & P-value \\
\cline { 2 - 5 } & Methoxyflurane $\mathbf{( n = 4 7 )}$ & Placebo $\mathbf{( n = 4 8 )}$ & $\mathbf{9 5 \%} \mathbf{C l})$ \\
\hline Overall & -29.0 & -19.1 & $-9.9(-17.4,-2.4)$ & 0.0104 \\
5 minutes & -24.5 & -14.6 & $-9.9(-17.5,-2.2)$ & $-9.3(-17.2,-1.4)$ \\
10 minutes & -28.1 & -18.8 & $-12.4(-21.9,-2.9)$ & \\
15 minutes & -31.6 & -19.2 & $-8.0(-17.4,1.5)$ & \\
20 minutes & -31.7 & -23.7 & \\
\hline
\end{tabular}

Notes: Pain scores recorded following the start of the planned emergency department procedure were excluded from the analysis. Pain scores taken after initiation of rescue medication were included in the analysis. a Least squares mean adjusted for baseline VAS pain score and time by treatment interaction.

and nine (18.8\%) placebo-treated patients, with a shorter time between dispensing the first and second inhalers for the placebo patients (median: 30 minutes; range: 1-63 minutes) compared with the methoxyflurane patients (median 58 minutes; range: 43-65 minutes). The diluter hole was covered during use by slightly more patients using the placebo inhalers (31 patients [64.6\%]) compared with the methoxyflurane inhalers (25 patients [53.2\%]).

Only two patients $(4.3 \%)$ in the methoxyflurane group and three patients $(6.3 \%)$ in the placebo group requested rescue medication (prior to censoring), and therefore no significant difference between the treatment groups in the time to request for rescue medication was identifiable (HR: 0.31 ; 95\% CI: $0.03,2.97 ; P=0.3085)$. The median time to request for rescue medication could not be estimated due to the low number of patients requesting rescue medication.

\section{Satisfaction with treatment}

Satisfaction with study treatment was significantly higher in the methoxyflurane group compared with the placebo 
group across all GMP ratings ( $P \leq 0.0012$, Figure 3$)$. Over $95 \%$ of treating physicians, research nurses, and patients rated methoxyflurane treatment as "Excellent", "Very Good" or "Good", compared with between $64 \%$ and $68 \%$ for placebo.

\section{Safety}

Treatment-emergent adverse events (TEAEs) are presented in Table 3. Fifty-five TEAEs were reported by 24 patients

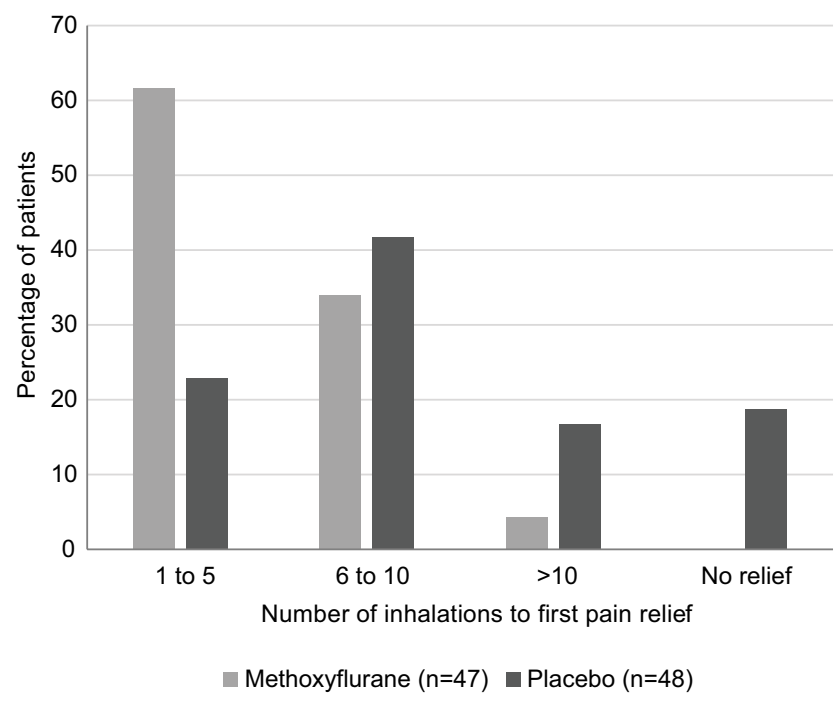

Figure 2 Number of inhalations to first pain relief (modified intention-to-treat population).
$(51.1 \%)$ in the methoxyflurane group and 35 TEAEs were reported by 20 patients $(41.7 \%)$ in the placebo group. Fifteen TEAEs in eleven (23.4\%) methoxyflurane-treated patients and six TEAEs in five (10.4\%) placebo-treated patients were considered to be related to study treatment according to the investigator's causality assessment. The most commonly reported TEAEs (reported by $\geq 3$ patients in either treatment group) were headache, dizziness, somnolence, and influenza-like illness. Dizziness and somnolence were more common in methoxyflurane-treated patients, influenza-like illness was more common in placebo-treated patients, and headache was reported at a similar frequency in both groups. The majority of TEAEs were mild and self-limiting; no patients experienced a severe or serious adverse event. In methoxyflurane-treated patients, most cases of dizziness commenced within 5 minutes of the start of dosing and resolved within 1 minute to 3 hours, somnolence events started within 2 hours of the start of dosing and resolved within 2 hours, while headache was generally reported in the period between ED discharge and followup. Four patients withdrew due to a TEAE: two patients $(4.3 \%)$ in the methoxyflurane group (one patient due to feeling dizzy and one patient due to light-headedness, bad taste and burning in his mouth) and two patients (4.2\%) in the placebo group (one patient due to light-headedness and nausea and one patient due to loss of consciousness lasting for $\sim 1$ minute).

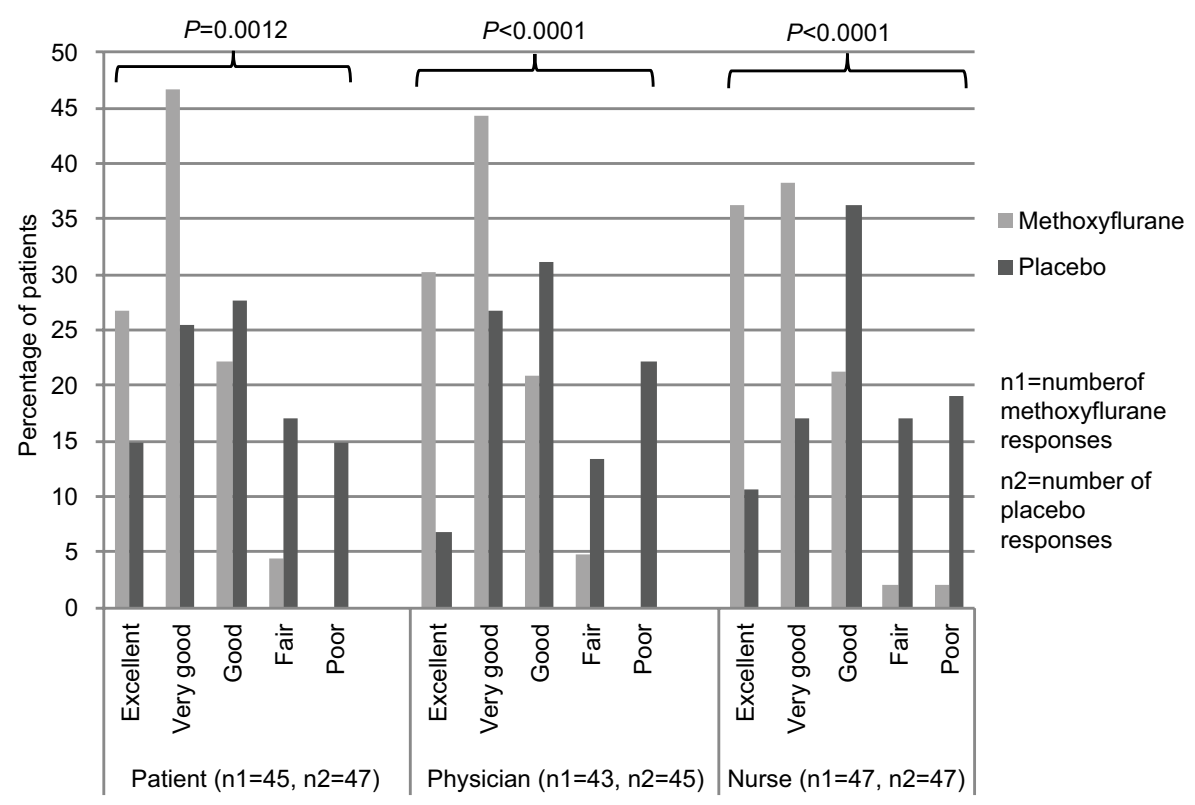

Figure 3 Satisfaction with treatment (global medication performance; modified intention-to-treat population).

Notes: $P$-values are for the significance of the treatment effect based on proportional odds model adjusted for baseline visual analog scale pain score. 
Table 3 Treatment-emergent adverse events (safety population)

\begin{tabular}{|c|c|c|c|c|c|c|}
\hline \multirow{2}{*}{$\begin{array}{l}\text { MedDRA system organ class } \\
\text { preferred term }\end{array}$} & \multicolumn{3}{|c|}{ Methoxyflurane $(n=47)$} & \multicolumn{3}{|c|}{ Placebo $(n=48)$} \\
\hline & $\begin{array}{l}\text { Number of } \\
\text { events }\end{array}$ & $\begin{array}{l}\text { Number of } \\
\text { patients }\end{array}$ & $\begin{array}{l}\text { Percentage } \\
\text { of patients }\end{array}$ & $\begin{array}{l}\text { Number of } \\
\text { events }\end{array}$ & \begin{tabular}{|l|} 
Number of \\
patients
\end{tabular} & $\begin{array}{l}\text { Percentage } \\
\text { of patients }\end{array}$ \\
\hline Any adverse event & 55 & 24 & 51.1 & 35 & 20 & 41.7 \\
\hline Ear and labyrinth disorders & 1 & 1 & 2.1 & 0 & 0 & 0.0 \\
\hline Tinnitus & 1 & 1 & 2.1 & 0 & 0 & 0.0 \\
\hline Gastrointestinal disorders & 3 & 3 & 6.4 & 1 & I & 2.1 \\
\hline Abdominal pain & 1 & I & 2.1 & 0 & 0 & 0.0 \\
\hline Nausea & 0 & 0 & 0.0 & I & I & 2.1 \\
\hline Oral discomfort & 1 & 1 & 2.1 & 0 & 0 & 0.0 \\
\hline Toothache & 1 & I & 2.1 & 0 & 0 & 0.0 \\
\hline General disorders and administration site conditions & 2 & 2 & 4.3 & 4 & 4 & 8.3 \\
\hline Chest pain & 0 & 0 & 0.0 & I & 1 & 2.1 \\
\hline Feeling drunk & 1 & 1 & 2.1 & 0 & 0 & 0.0 \\
\hline Influenza-like illness & 0 & 0 & 0.0 & 3 & 3 & 6.3 \\
\hline Medical device complication & 1 & I & 2.1 & 0 & 0 & 0.0 \\
\hline Infections and infestations & 4 & 3 & 6.4 & $\mathrm{I}$ & 1 & 2.1 \\
\hline Influenza & 0 & 0 & 0.0 & I & I & 2.1 \\
\hline Nasopharyngitis & 1 & 1 & 2.1 & 0 & 0 & 0.0 \\
\hline Rhinitis & 1 & 1 & 2.1 & 0 & 0 & 0.0 \\
\hline Viral infection & 2 & 2 & 4.3 & 0 & 0 & 0.0 \\
\hline Injury, poisoning, and procedural complications & 6 & 4 & 8.5 & I & I & 2.1 \\
\hline Fall & 2 & 2 & 4.3 & 0 & 0 & 0.0 \\
\hline Joint sprain & 2 & 2 & 4.3 & 0 & 0 & 0.0 \\
\hline Limb injury & 1 & I & 2.1 & 0 & 0 & 0.0 \\
\hline Thermal burn & 0 & 0 & 0.0 & I & 1 & 2.1 \\
\hline Upper limb fracture & I & 1 & 2.1 & 0 & 0 & 0.0 \\
\hline Investigations & 0 & 0 & 0.0 & I & 1 & 2.1 \\
\hline Blood pressure diastolic decreased & 0 & 0 & 0.0 & I & I & 2.1 \\
\hline Musculoskeletal and connective tissue disorders & 2 & 2 & 4.3 & 4 & 4 & 8.3 \\
\hline Arthralgia & 0 & 0 & 0.0 & 1 & I & 2.1 \\
\hline Back pain & 2 & 2 & 4.3 & 2 & 2 & 4.2 \\
\hline Myalgia & 0 & 0 & 0.0 & 1 & 1 & 2.1 \\
\hline Nervous system disorders & 32 & 19 & 40.4 & 17 & 13 & 27.1 \\
\hline Dizziness & 7 & 7 & 14.9 & 1 & 1 & 2.1 \\
\hline Dysgeusia & 1 & 1 & 2.1 & 0 & 0 & 0.0 \\
\hline Headache & 20 & 12 & 25.5 & 15 & 11 & 22.9 \\
\hline Loss of consciousness & 0 & 0 & 0.0 & 1 & 1 & 2.1 \\
\hline Somnolence & 3 & 3 & 6.4 & 0 & 0 & 0.0 \\
\hline Syncope & 1 & I & 2.1 & 0 & 0 & 0.0 \\
\hline Reproductive system and breast disorders & 1 & 1 & 2.1 & 0 & 0 & 0.0 \\
\hline Dysmenorrhea & I & 1 & 2.1 & 0 & 0 & 0.0 \\
\hline Respiratory, thoracic, and mediastinal disorders & 1 & 1 & 2.1 & 2 & I & 2.1 \\
\hline Nasal congestion & 0 & 0 & 0.0 & I & I & 2.1 \\
\hline Oropharyngeal pain & 1 & I & 2.1 & $\mathrm{I}$ & I & 2.1 \\
\hline Skin and subcutaneous tissue disorders & 2 & 2 & 4.3 & 2 & I & 2.1 \\
\hline Hypoesthesia facial & 1 & 1 & 2.1 & 0 & 0 & 0.0 \\
\hline Rash & 0 & 0 & 0.0 & 2 & I & 2.1 \\
\hline Rash pruritic & I & I & 2.1 & 0 & 0 & 0.0 \\
\hline Vascular disorders & I & 1 & 2.1 & 2 & 2 & 4.2 \\
\hline Hypotension & 1 & I & 2.1 & 2 & 2 & 4.2 \\
\hline
\end{tabular}

Notes: Includes events reported up to $14 \pm 2$ days after discharge from the emergency department. Only events not related to the trauma presentation were recorded. Abbreviation: MedDRA, Medical Dictionary for Regulatory Activities.

Inspection of individual patient vital signs showed no observable effects of low-dose methoxyflurane on cardiovascular or respiratory parameters. Glasgow coma score was 15 across all patients and observations. Although clinical laboratory sampling was limited, examination of clinical chemistry results did not identify any renal or hepatic damage in the methoxyflurane group. 


\section{Discussion}

This subgroup analysis shows that methoxyflurane provided rapid and effective pain relief in adolescent patients with acute trauma pain, with both patients and HCPs expressing a high level of treatment satisfaction. The treatment difference (methoxyflurane-placebo) in the primary analysis of the VAS pain intensity score over the first 20 minutes of treatment was smaller for adolescent patients $(-9.9 \mathrm{~mm}$ [95\% CI: -17.4 , $-2.4 \mathrm{~mm}])$ compared with adult patients $(-17.4 \mathrm{~mm}[95 \%$ CI: $-22.3,-12.5 \mathrm{~mm}]) .^{35}$ This appears to be due to a much larger "placebo-effect" in the adolescent population; while the overall adjusted mean change from baseline in VAS pain intensity with methoxyflurane was the same for adult and adolescent patients $(-29.0 \mathrm{~mm})$; it was noticeably different for adult $(-11.6 \mathrm{~mm})$ and adolescent $(-19.1 \mathrm{~mm})$ patients in the placebo group. Whilst the difference was statistically significant, this phenomenon resulted in the treatment difference for the adolescent subgroup being less than the minimum clinically significant change in acute pain of 13 $\mathrm{mm}$ on a $100 \mathrm{~mm}$ VAS scale previously suggested by Todd et al in a hypothesis-generating study in trauma patients. ${ }^{42}$ For secondary pain relief and satisfaction (GMP) endpoints, the results for the adolescent subgroup were generally positive and continued to show a larger placebo effect compared with the adult subgroup. ${ }^{35}$ In the adult subgroup, $82.4 \%$ of methoxyflurane-treated patients and $52.5 \%$ of placebotreated patients experienced pain relief within a median of 5 and 20 minutes, respectively, ${ }^{35}$ compared with $97.9 \%$ of methoxyflurane-treated patients and $81.3 \%$ of placebo-treated patients within a median of 1 and 3 minutes, respectively for adolescent patients. GMP of methoxyflurane was rated as "Excellent", "Very good" or "Good" for approximately $75 \%$ of adult patients and $>95 \%$ of adolescent patients, while placebo treatment received the same ratings for $26 \%-31 \%$ of adult patients and $64 \%-68 \%$ of adolescent patients. Despite the strong placebo effect in adolescent patients, a significant treatment difference in favor of methoxyflurane was shown for all secondary efficacy endpoints, with the exception of time to request for rescue medication (only five patients in total requested rescue medication). Although few placebotreated patients requested rescue medication, the shorter time to request for a second inhaler and higher number of patients covering the diluter hole in the placebo group are suggestive of additional need for analgesia in this group.

The placebo effect is well recognized in adults but is less well studied in children. ${ }^{43}$ However, it is likely that in our adolescent subgroup, verbally-induced expectations of potential benefit and physician/nurse-child-parent interactions had an influence on perception of pain and perceived benefit of treatment. Approximately $80 \%$ of children are considered suggestible compared to $15 \%$ in the adult population, ${ }^{44}$ and work on the impact of suggestions on pain perception and placebo analgesia has shown a 5 -fold (heat pain tolerance) and 3-fold (heat pain threshold) greater effect in children ${ }^{45}$ compared with adults. ${ }^{46}$

The rapid onset of analgesia with methoxyflurane and the degree of reduction in VAS pain intensity in this adolescent subgroup is comparable to that described in previous observational case series of its use in children (reported on 11-point pain scales). Babl et al reported a drop in mean $(95 \% \mathrm{CI})$ paramedic numerical pain scores from $7.9(7.5-8.3)$ at baseline to $4.5(3.9-5.0)$ at $2-5$ minutes and $3.2(2.8-3.7)$ at 10 minutes in 105 children mostly with extremity injuries. ${ }^{30}$ Gillis et al found a similar decrease in average pain score from 7.6 \pm 1.7 on arrival to $5.3 \pm 2.1$ and $4.3 \pm 2.3$ after 15 and 30 minutes' treatment in the ED in a mixed population of 59 pediatric and adult patients with trauma pain. ${ }^{31}$ Another observational case series of 14 children investigating methoxyflurane for procedural analgesia or as a bridging agent in the ED reported onset of analgesia within 2-5 minutes, adequate analgesia in $71 \%$ of patients, and high patient/parent/HCP satisfaction with analgesia. ${ }^{47}$ These studies were observational and uncontrolled; however, an earlier pilot randomized, doubleblind, placebo-controlled trial in 41 children with upper limb fractures by Chin et al showed a 2.7 point greater reduction in pain score at 10 minutes for methoxyflurane (4.0) compared with placebo $(1.3 ; P<0.05) .{ }^{33}$ Interestingly, this study by Chin et al did not show such a strong placebo effect as our adolescent subgroup analysis. Although these studies used 11-point pain scales rather than the $100 \mathrm{~mm}$ VAS used in the STOP! study, the degree of pain relief reported with methoxyflurane is similar to our findings in the adolescent subgroup analysis of the STOP! study.

The reduction in pain intensity observed with methoxyflurane in this adolescent subgroup is comparable with that observed for IV morphine and IN fentanyl in a similar study by Borland et al that enrolled children with acute long-bone fractures. ${ }^{48}$ Borland et al reported mean changes from baseline in VAS pain at 5, 10, and 20 minutes of $-25 \mathrm{~mm},-26$ $\mathrm{mm}$, and $-32 \mathrm{~mm}$ for morphine and $-13 \mathrm{~mm},-22 \mathrm{~mm}$, and $-31 \mathrm{~mm}$ for fentanyl (from a baseline mean of $67 \mathrm{~mm}$ and $68 \mathrm{~mm}$, respectively); similar to results for methoxyflurane of $-25 \mathrm{~mm},-28 \mathrm{~mm}$, and $-32 \mathrm{~mm}$ from a baseline of 62 $\mathrm{mm}$ in this adolescent subgroup analysis. This is in contrast with findings of a large $(\mathrm{N}=3,312)$, retrospective comparative study of IV morphine, IN fentanyl, and methoxyflurane in 
the prehospital treatment of children with moderate-to-severe acute pain by Bendall et al, which found that methoxyflurane was significantly less effective than morphine and fentanyl, providing effective analgesia for $78.3 \%$ of patients, compared with $87.5 \%$ for morphine and $89.5 \%$ for fentanyl. ${ }^{32}$ While methoxyflurane was found to be significantly less effective than IV morphine and IN fentanyl in Bendall et al's study, methoxyflurane still provided effective analgesia for a large majority of children (78.3\%) and may be a preferred treatment option given its ease of use and concerns regarding opioid-related side effects. ${ }^{49,50}$ Furthermore, clinical studies of methoxyflurane as procedural analgesia have suggested that it has anxiolytic properties, which may also be of benefit in distressed children with trauma injuries..$^{51,52}$

Although the STOP! study is one of very few prospective studies of methoxyflurane, a weakness of the study is that it was placebo-controlled rather than using an active comparator. ${ }^{53}$ This approach was taken due to the difficulties in double-blinding a comparator study, due to the distinctive mode of administration and odor of methoxyflurane, equipment needed for administration of nitrous oxide, and the slow onset of action of possible oral comparators such as acetaminophen or non-steroidal anti-inflammatories, as previously discussed by Coffey et al. ${ }^{35}$ Another placebo-controlled trial investigating the efficacy and safety of methoxyflurane for acute, trauma-related pain in 220 children aged 6-17 years is ongoing in the UK, which will provide further data on pediatric use. ${ }^{54}$

To our knowledge, no prospective studies comparing methoxyflurane with other analgesics for acute pediatric trauma pain have previously been reported. However, in a prospective cohort study, methoxyflurane had a more rapid onset of analgesic action than tramadol in 40 adult patients with ankle injuries in the ED. ${ }^{55} \mathrm{~A}$ further prospective randomized study of methoxyflurane vs IV midazolam and fentanyl for procedural analgesia during colonoscopy by Nguyen et al found methoxyflurane to be equally effective with a shorter recovery time. ${ }^{52}$ Further prospective studies are needed to provide direct evidence of the effectiveness of methoxyflurane analgesia compared with other analgesic agents, and a prospective open randomized study comparing pain relief between methoxyflurane and standard of care for treating patients with trauma pain in Spanish EDs (InMEDIATE) has recently completed. ${ }^{56}$

Deep sedation has occasionally been reported with methoxyflurane use in younger children under $5,{ }^{30}$ but this has not been observed in studies enrolling older children ${ }^{47}$ and was not reported in our adolescent subgroup. The most common adverse events in the methoxyflurane group were headache $(25.5 \%)$, dizziness $(14.9 \%)$, and somnolence (6.4\%), which are all expected events ${ }^{24}$ and were generally brief and self-limiting, resolving soon after cessation of therapy. Two patients discontinued use of methoxyflurane due to adverse events (one patient due to feeling dizzy and one patient due to light-headedness, bad taste and burning in his mouth), but the majority of patients, research nurses, and physicians rated their satisfaction with methoxyflurane treatment highly ( $>95 \%$ assessing treatment as "Excellent", "Very Good" or "Good"). We found no detectable effect of methoxyflurane on the cardiovascular system or respiratory system in this adolescent subgroup, which is in agreement with the results of two earlier retrospective observational studies ${ }^{26,57}$ using data from Australian ambulance services. In addition, there was no indication of any renal or hepatic effects of methoxyflurane in this subgroup analysis, or in a previous large controlled observational study of 135,770 patients receiving emergency prehospital analgesia in Australia (13\% of whom received methoxyflurane).$^{58}$

\section{Conclusion}

The results of this adolescent subgroup analysis of the STOP! study show that low-dose inhaled methoxyflurane is an effective and well tolerated analgesic with fast onset of action in children aged 12-17 years with moderate-tosevere acute trauma pain, with no evidence that the efficacy or safety profile for such children differs to that reported in adults. Further data from prospective randomized studies with active comparators are needed to help inform optimal treatment strategies, but with its simple non-invasive method of administration and rapid onset of action, and favorable safety profile, methoxyflurane may have the potential to overcome some of the barriers to effective analgesia in adolescent patients.

\section{Data sharing statement}

Medical Developments International Limited are currently finalizing our Data Sharing Policy. The Data Sharing Policy will adhere to all ICMJE recommendations. If you have any questions or would like to request data please get in touch via the following e-mail address: clinicaltrials@medicaldev.com.

\section{Acknowledgments}

Penthrox $^{\circledR}$ is a registered trade mark of Medical Developments International (MDI) Limited and used under license. The study was funded by MDI Limited. This article was supported by Mundipharma Research Limited. 
Editorial assistance in the preparation of this manuscript was provided by Karen Mower of Scientific Editorial and funded by Mundipharma Research Limited.

\section{Author contributions}

All authors contributed to data analysis, drafting and revising the article, gave final approval of the version to be published, and agree to be accountable for all aspects of the work.

\section{Disclosure}

Stuart Hartshorn reports a Chief Investigator grant and personal fees from MDI Limited outside of the submitted work. Patrick Dissmann reports personal fees from Mundipharma International, outside the submitted work. Frank Coffey reports grants from Nottingham University Hospital Trust, during the conduct of the study. Mark Lomax is an employee of Mundipharma Research Limited. The authors report no other conflicts of interest in this work.

\section{References}

1. Cordell WH, Keene KK, Giles BK, Jones JB, Jones JH, Brizendine EJ. The high prevalence of pain in emergency medical care. Am J Emerg Med. 2002;20(3):165-169.

2. van Woerden G, van den Brand CL, den Hartog CF, Idenburg FJ, Grootendorst DC, van der Linden MC. Increased analgesia administration in emergency medicine after implementation of revised guidelines. Int J Emerg Med. 2016;9(1):4.

3. Pierik JG, Ijzerman MJ, Gaakeer MI, et al. Pain management in the emergency chain: the use and effectiveness of pain management in patients with acute musculoskeletal pain. Pain Med. 2015;16(5):970-984.

4. Motov SM, Khan AN. Problems and barriers of pain management in the emergency department: are we ever going to get better? J Pain Res. 2008;2:5-11.

5. Carter D, Sendziuk P, Eliott JA, Braunack-Mayer A. Why is pain still Under-Treated in the emergency department? Two new hypotheses. Bioethics. 2016;30(3):195-202.

6. Pierik JGJ, Ijzerman MJ, Gaakeer MI, Vollenbroek-Hutten MMR, Doggen CJM. Painful discrimination in the emergency department: risk factors for Underassessment of patients' pain by nurses. J Emerg Nurs. 2017;43(3):228-238.

7. Albrecht E, Taffe P, Yersin B, Schoettker P, Decosterd I, Hugli O. Undertreatment of acute pain (oligoanalgesia) and medical practice variation in prehospital analgesia of adult trauma patients: a $10 \mathrm{yr}$ retrospective study. Br J Anaesth. 2013;110(1):96-106.

8. Thomas D, Kircher J, Plint AC, et al. Pediatric pain management in the emergency department: the triage nurses' perspective. J Emerg Nurs. 2015;41(5):407-413.

9. Browne LR, Studnek JR, Shah MI, Brousseau DC, Guse CE, Lerner EB. Prehospital opioid administration in the emergency care of injured children. Prehosp Emerg Care. 2016;20(1):59-65.

10. Browne LR, Shah MI, Studnek JR, et al. Multicenter evaluation of prehospital opioid pain management in injured children. Prehosp Emerg Care. 2016;20(6):759-767.

11. Murphy A, Mccoy S, O’Reilly K, et al. A prevalence and management study of acute pain in children attending emergency departments by ambulance. Prehosp Emerg Care. 2016;20(1):52-58.

12. Lord B, Jennings PA, Smith K. The epidemiology of pain in children treated by paramedics. Emerg Med Australas. 2016;28(3):319-324.
13. Rutkowska A, Skotnicka-Klonowicz G. Prehospital pain management in children with traumatic injuries. Pediatr Emerg Care. 2015;31(5):317-320.

14. Dong L, Donaldson A, Metzger R, Keenan H. Analgesic administration in the emergency department for children requiring hospitalization for long-bone fracture. Pediatr Emerg Care. 2012;28(2):1-114.

15. Milani GP, Benini F, Dell'era L, et al. Acute pain management: acetaminophen and ibuprofen are often under-dosed. Eur J Pediatr. 2017;176(7):979-982.

16. Hartshorn S, O’Sullivan R, Maconochie IK, Bevan C, Cleugh F, Lyttle M. Paediatric emergency Researcg in the UK and Ireland (PERUKI). establishing the research priorities of paediatric emergency medicine clinicians in the UK and ireland. Emerg Med J. 2015;32(11):864-868.

17. Browne LR, Shah MI, Studnek JR, et al. 2015 pediatric research priorities in prehospital care. Prehosp Emerg Care. 2016;20(3):311-316.

18. Tomi K, Mashimo T, Tashiro C, et al. Alterations in pain threshold and psychomotor response associated with subanaesthetic concentrations of inhalation anaesthetics in humans. Br J Anaesth. 1993;70(6): 684-686.

19. Crandell WB, Pappas SG, Macdonald A. Nephrotoxicity associated with methoxyflurane anesthesia. Anesthesiology. 1966;27(5):591-607.

20. Mazze RI, Shue GL, Jackson SH. Renal dysfunction associated with methoxyflurane anesthesia. A randomized, prospective clinical evaluation. JAMA. 1971;216(2):278-288

21. Mazze RI. Methoxyflurane revisited: tale of an anesthetic from cradle to Grave. Anesthesiology. 2006;105(4):843-846.

22. Australian Therapeutic Goods administration Approved product information for Penthrox; 2016. Available from: https://www.ebs.tga.gov.au/ ebs/picmi/picmirepository.nsf/PICMI?OpenForm\&t=pi\&q=methoxyfl urane. Accessed September 03, 2018.

23. New Zealand Datasheet for Penthrox; 2017. Available from: http:// www.medsafe.govt.nz/profs/datasheet/p/penthroxinh.pdf. Accessed September 03, 2018.

24. Penthrox ${ }^{\circledR}$ summary of product characteristics. Available from: https:// www.medicines.org.uk/emc/medicine/31391. Accessed September 03, 2018.

25. Grindlay J, Babl FE. Review article: efficacy and safety of methoxyflurane analgesia in the emergency department and prehospital setting. Emerg Med Australas. 2009;21(1):4-11.

26. Johnston S, Wilkes GJ, Thompson JA, Ziman M, Brightwell R. Inhaled methoxyflurane and intranasal fentanyl for prehospital management of visceral pain in an Australian ambulance service. Emerg Med J. 2011;28(1):57-63.

27. Buntine P, Thom O, Babl F, Bailey M, Bernard S. Prehospital analgesia in adults using inhaled methoxyflurane. Emerg Med Australas. 2007;19(6):509-514.

28. Gaskell AL, Jephcott CG, Smithells JR, Sleigh JW. Self-administered methoxyflurane for procedural analgesia: experience in a tertiary Australasian centre. Anaesthesia. 2016;71(4):417-423.

29. Dayan AD. Analgesic use of inhaled methoxyflurane: evaluation of its potential nephrotoxicity. Hum Exp Toxicol. 2016;35(1):91-100.

30. Babl FE, Jamison SR, Spicer M, Bernard S. Inhaled methoxyflurane as a prehospital analgesic in children. Emerg Med Australas. 2006;18(4):404-410.

31. Gillis M, Keirens A, Steinkamm C, Verbelen J, Muysoms W, Reynders N. The use of methoxyflurane (penthrox) in the emergency department. Reg Anesth Pain Med. 2008;33(Sup 1):e247.

32. Bendall JC, Simpson PM, Middleton PM. Effectiveness of prehospital morphine, fentanyl, and methoxyflurane in pediatric patients. Prehosp Emerg Care. 2011;15(2):158-165.

33. Chin R, Mccaskill M, Browne G, Lam L. A randomized controlled trial of inhaled methoxyflurane pain relief in children with upper limb fracture. J Paediatr Child Health. 2002;38:A13-14.

34. Coffey F, Wright J, Hartshorn S, et al. Stop!: a randomised, double-blind, placebo-controlled study of the efficacy and safety of methoxyflurane for the treatment of acute pain. Emerg Med J. 2014;31(8):613-618. 
35. Coffey F, Dissmann P, Mirza K, Lomax M. Methoxyflurane analgesia in adult patients in the emergency department: a subgroup analysis of a randomized, double-blind, placebo-controlled study (stop!). Adv Ther. 2016;33(11):2012-2031.

36. Crankshaw DP, Eagle a, Komesaroff D. Methoxyflurane dosage with the Penthrox inhaler for analgesia during short painful procedures [abstract]. Anaesth Intensive Care. 2004;32(3):428.

37. CHMP guideline CPMP/EWP/612/00. Note for guidance on clinical investigations of medicinal products for treatment of nociceptive pain; 2002. Available from: https://www.ema.europa.eu/documents/scientificguideline/note-guidance-clinical-investigation-medicinal-productstreatment-nociceptive-pain_en.pdf. Accessed February 07, 2019.

38. Jensen MP, Karoly P, Braver S. The measurement of clinical pain intensity: a comparison of six methods. Pain. 1986;27(1):117-126.

39. Ho K, Spence J, Murphy MF. Review of pain-measurement tools. Ann Emerg Med. 1996;27(4):427-432.

40. Gallagher EJ, Liebman M, Bijur PE. Prospective validation of clinically important changes in pain severity measured on a visual analog scale. Ann Emerg Med. 2001;38(6):633-638.

41. Collins SL, Moore RA, Mcquay HJ. The visual analogue pain intensity scale: what is moderate pain in millimetres? Pain 1997;72(1-2):95-97.

42. Todd KH, Funk KG, Funk JP, Bonacci R. Clinical significance of reported changes in pain severity. Ann Emerg Med. 1996;27(4):485-489.

43. Simmons K, Ortiz R, Kossowsky J, et al. Pain and placebo in pediatrics: a comprehensive review of laboratory and clinical findings. Pain. 2014;155(11):2229-2235.

44. Parellada M, Moreno C, Moreno M, Espliego A, de Portugal E, Arango C. Placebo effect in child and adolescent psychiatric trials. Eur Neuropsychopharmacol. 2012;22(11):787-799.

45. Krummenacher P, Kossowsky J, Schwarz C, et al. Expectancy-induced placebo analgesia in children and the role of magical thinking. J Pain. 2014;15(12):1282-1293.

46. Krummenacher P, Candia V, Folkers G, Schedlowski M, Schönbächler G. Prefrontal cortex modulates placebo analgesia. Pain. 2010;148(3):368-374.

47. Babl F, Barnett P, Palmer G, Oakley E, Davidson A. A pilot study of inhaled methoxyflurane for procedural analgesia in children. Paediatr Anaesth. 2007;17(2):148-153.

48. Borland M, Jacobs I, King B, O'Brien D. A randomized controlled trial comparing intranasal fentanyl to intravenous morphine for managing acute pain in children in the emergency department. Ann Emerg Med. 2007;49(3):335-340.
49. Hartling L, Ali S, Dryden DM, et al. How safe are common analgesics for the treatment of acute pain for children? A systematic review. Pain Res Manag. 2016;2016(2):1-15.

50. Kendall J, Maconochie I, Wong IC, Howard R, Study D, DIASAFE study. A novel multipatient intranasal diamorphine spray for use in acute pain in children: pharmacovigilance data from an observational study. Emerg Med J. 2015;32(4):269-273.

51. Nguyen N, Toscano L, Lawrence M, et al. Portable inhaled methoxyflurane is feasible and safe for colonoscopy in subjects with morbid obesity and/or obstructive sleep apnea. Endosc Int Open. 2015;03(05): E487-E493.

52. Nguyen NQ, Toscano L, Lawrence M, et al. Patient-controlled analgesia with inhaled methoxyflurane versus conventional endoscopist-provided sedation for colonoscopy: a randomized multicenter trial. Gastrointest Endosc. 2013;78(6):892-901.

53. Carley S, Body R. Methoxyflurane is a better painkiller than placebo: but do we want to know more? Emerg Med J. 2014;31(8):610.

54. Medical Developments International Limited. A randomised, doubleblind, multicentre, placebo controlled study to evaluate the safety and efficacy of methoxyflurane (PENTHROX $®$ ) for the treatment of acute pain in children and adolescents from 6 to less than 18 years of AGE (presenting to an emergency department with minor trauma). Available from: https://clinicaltrials.gov/ct2/show/NCT03215056?term=NCT032 15056\&rank=1. ClinicalTrials.gov Identifier NCT03215056. Accessed September 03, 2018.

55. Konkayev AK, Baymagambetov S, Sainov M. Evaluation of clinical effectiveness of inhalatory analgesic 'Penthrox' for pain relief in ankle injuries. Arch Balk Med Union. 2013;48:239-243.

56. Borobia Pérez AM, Capilla Pueyo R, Casal Codesido JR, et al. InMEDIATE group. Phase IIIB, open label randomised clinical trial to compare pain relief between methoxyflurane and standard of care for treating patients with trauma pain in Spanish emergency units (InMEDIATE): study protocol. IBJ Clin Pharmacol. 2017;1:e0008.

57. Oxer HF. Effects of Penthrox ${ }^{\circledR}$ (methoxyflurane) as an analgesic on cardiovascular and respiratory functions in the pre-hospital setting. $J$ Mil Veterans Health. 2016;24(2):14-20.

58. Ig J, Jacobs IG. Health effects of patient given methoxyflurane in the pre-hospital setting: a data linkage study. Open Emerg Med J. 2010;3:7-13.
Journal of Pain Research

\section{Publish your work in this journal}

The Journal of Pain Research is an international, peer reviewed, open access, online journal that welcomes laboratory and clinical findings in the fields of pain research and the prevention and management of pain. Original research, reviews, symposium reports, hypothesis formation and commentaries are all considered for publication.

\section{Dovepress}

The manuscript management system is completely online and includes a very quick and fair peer-review system, which is all easy to use. Visit http://www.dovepress.com/testimonials.php to read real quotes from published authors. 